Cintra, A. D - Bulas de medicamentos

\title{
Bulas de medicamentos alemãs e brasileiras em contraste: alguns resultados da análise linguística
}

German and Brazilian package inserts in contrast: partial results of a linguistic analysis

\section{Adriana Dominici Cintra*}

\begin{abstract}
This research, a linguistic contrastive study of package inserts' texts from Germany and Brazil, was developed with the aim to verify differences and similarities between them. To achieve this purpose, 20 package inserts were compared in their macro and microstructure surfaces, after a detailed investigation of the genre's main characteristics. As a result of the analysis, it was possible to confirm the presence of convergences and divergences in the Brazilian and German package inserts and identify some reasons for their existence.
\end{abstract}

Keywords: Contrastive linguistics; Contrastive textology; Package Insert

Resumo: Na presente pesquisa foi desenvolvido um estudo linguístico contrastivo de textos de bulas de medicamentos da Alemanha e do Brasil com o objetivo de verificar a existência de diferenças e semelhanças entre eles. Para isso, um total de 20 bulas foram comparadas em seus níveis macro e microestrutural, após uma investigação detalhada das principais características do gênero em questão. Ao final da análise contrastiva, foi confirmada a presença de convergências e divergências no gênero, tendo em vista o par linguístico adotado, e também identificadas algumas explicações para tal.

Palavras-chave: Linguística textual; Textologia contrastiva; Bula de medicamento

\footnotetext{
* Mestranda em Língua e Linguística Alemã pela FFLCH-USP; email: adriana.cintra@usp.br. Este artigo é baseado na pesquisa de iniciação científica desenvolvida pela autora em 2011-2012, sob orientação da Profa. Dra. Tinka Reichmann e com financiamento da Fundação de Amparo à Pesquisa do Estado de São Paulo (FAPESP).
} 


\section{Cintra, A. D - Bulas de medicamentos}

\section{Introdução}

De acordo com o objetivo geral estabelecido para o presente estudo, que é comparar linguisticamente uma amostra de um tipo textual escrito em duas línguas diferentes e inserido em dois cenários distintos, a principal base teórica adotada para tal análise foi a que se refere à disciplina da Textologia Contrastiva. Essa subárea da linguística textual teve seus estudos iniciados na década de 80, após a chamada 'virada pragmática' [pragmatische Wende] (FIX 2009: 12), que marcou uma mudança de paradigma na linguística. Nesse momento, os estudos linguísticos deixam de observar a língua como um sistema e passam a relacioná-la com suas funções e poder de comunicação.

HARTMANN (1980: 32), em estudo precursor sobre textologia contrastiva, definiu que a disciplina seria uma combinação de análise do discurso e linguística contrastiva, cujas questões centrais buscam verificar se convenções textuais/discursivas diferem de uma língua para outra e se os estilos narrativos de cada uma das línguas influenciam, em vários níveis, as escolhas do emissor da mensagem.

A ideia de agregar os conhecimentos dos gêneros textuais a esse tipo de análise contrastiva só foi implementada uma década depois, no âmbito do projeto de Textologia Contrastiva da Universidade de Salzburg (1994), que aliou essa corrente ao interesse de pesquisar as diferenças interlinguais de diversos gêneros textuais, permitindo uma concepção comunicativa do texto, com foco na sua respectiva prática cotidiana (Melo/Monteiro 2008: 223). A princípio, os objetivos gerais e mais comuns das pesquisas com gêneros textuais consistiam em identificar quais deles são os mais relevantes socialmente e descrever seus principais aspectos constitutivos. Entre os objetivos específicos figuravam, por exemplo, a identificação de diferenças culturais em textos pertencentes ao mesmo gênero e questões acerca da classificação dos gêneros textuais e seus critérios.

Nesta pesquisa, adotamos a perspectiva interacional segundo a seguinte definição: "Gêneros textuais são modelos convencionalizados, vigentes em situações linguísticas complexas e podem ser descritos como conjunto típico de características contextuais 


\section{Cintra, A. D - Bulas de medicamentos}

(situativas), comunicativo-funcionais e estruturais (gramaticais e temáticas)" (BRINKER 2010: 125) ${ }^{1}$. Esta definição toma os gêneros textuais como combinações típicas de determinados fatores situativos e características funcionais e estruturais.

Entretanto, de acordo com FIX (2009: 15), os gêneros não são apenas grupos de textos com aspectos relativamente semelhantes, mas também artefatos culturais, cunhados por situações culturalmente específicas, já que "as comunidades dispõem de gêneros textuais como um meio de ação em determinadas situações culturalmente consolidadas" ${ }^{2}$. Isso significa que um mesmo gênero textual pode, portanto, sofrer variações nesse sentido, dependendo da cultura na qual está inserido. Como parte da rotina dos falantes de determinada comunidade linguística, os gêneros também são considerados parte importante na constituição da cultura de um povo, ou seja, tanto são influenciados por ela quanto a caracterizam. Sendo assim, entre as principais atividades linguístico-textuais que envolvem o aspecto cultural dos gêneros estão os estudos a respeito da influência das culturas (cf. FIX/HABSCHEID/KLEIN 2001), das diferenças interculturais no desenvolvimento de um gênero textual (cf. ADAMZIK 2001), das características do texto mais atingidas pela culturalidade (cf. BRINKER 2005), entre outros. Nesse âmbito, foram criadas condições propícias para que um ramo promissor da linguística textual se desenvolvesse, o da textologia contrastiva.

A seguir, serão apresentados os principais resultados obtidos a partir do estudo do gênero textual eleito, bem como da comparação desses textos em língua alemã e em português brasileiro. Alguns apontamentos adicionais relacionados à metodologia de pesquisa adotada serão comentados oportunamente, entretanto, o resumo da principal base teórica utilizada neste trabalho limitar-se-á a este item.

1 Textsorten sind konventionell geltende Muster für komplexe sprachliche Handlungen und lassen sich als jeweils typische Verbindungen von kontextuellen (situativen), kommunikativ-funktionalen und strukturellen (grammatischen und thematischen) Merkmalen beschreiben.

Pandaemonium, São Paulo, v. 15, n. 20, Dez. /2012, p. 224-261 - www.fflch.usp.br/dlm/alemao/pandaemoniumgermanicum 


\section{Cintra, A. D - Bulas de medicamentos}

\section{$2 \bigcirc$ gênero textual bula de medicamento e contextos analisados}

A bula de medicamentos é um texto que acompanha um produto. Tais textos são denominados 'textos técnicos' ou 'textos de especialidade' por apresentarem, normalmente, uma grande especificidade relacionada à área na qual estão inseridos.

No caso das bulas, trata-se de textos que, necessariamente, vêm junto com medicamentos e suas principais funções são informar sobre o medicamento e instruir a respeito de seu uso/aplicação. Sendo assim, as bulas pertencem às áreas de farmacêutica e medicina e, por isso, contêm uma quantidade significativa de termos técnicos relacionados, além de dados específicos e relevantes das áreas. Tendo em vista seus objetivos básicos, é possível dizer que tais textos estão inseridos em um âmbito comunicativo público, ou seja, são produzidos para serem recebidos por uma grande massa de leitores.

Normalmente, os textos técnicos ou de especialidade, como é o caso das bulas de medicamentos, são veiculados por escrito, entretanto, sabe-se que, atualmente, é muito comum que outros tipos de recursos dêem suporte informativo ao texto escrito, como ilustrações para auxiliar na compreensão das instruções de uso/aplicação e gráficos e tabelas para esclarecer melhor outras informações relevantes, como frequência de reações adversas e posologia ${ }^{3}$.

Quanto aos agentes de comunicação envolvidos com o texto da bula, há algumas observações importantes a serem feitas. A primeira delas é que não é possível determinar quem é (são) o(s) autor(es) desse texto, pois há muitas possibilidades e combinações, entre elas: um grupo de farmacêuticos do laboratório que comercializa o medicamento; um redator contratado pelo laboratório; adaptações de trechos de literatura técnica; adaptações de traduções de bulas de medicamentos importados. Dessa forma, apenas a empresa farmacêutica é citada explicitamente como responsável pela elaboração do texto da bula, não

2 Gemeinschaften verfügen über Textsorten als ein Mittel ihres Handelns in bestimmten kulturell verfestigten Situationen.

3 Posologia é a indicação da dosagem adequada de um medicamento para cada caso. (vide iDicionário Aulete) 


\section{Cintra, A. D - Bulas de medicamentos}

sendo identificável sua real autoria, nem a quantidade de colaboradores da mesma. O papel do autor é trazer informações necessárias ao leitor a respeito do medicamento (composição, indicações, contra-indicações, armazenamento) e instruí-lo no uso/aplicação desse. Sobre o(s) leitor(es) de uma bula de medicamentos, também não é possível fazer afirmações tão precisas, já que esse texto é produzido para uma grande massa de consumidores do medicamento (ou pacientes), ou seja, não há um grupo específico que possa ser caracterizado como principal receptor do texto, no qual sejam claramente identificados certos aspectos diferenciadores, como faixa etária, sexo, nível de escolaridade ou área de atuação, e todo consumidor é um leitor em potencial. Sobretudo devido ao objetivo de instruir, a comunicação entre autor e leitor é assimétrica e monológica - nesses casos, o autor é o único que tem algo a comunicar, ficando o leitor em uma posição passiva, apenas recebendo as informações e não contribuindo com a comunicação. Entretanto, durante a leitura do texto, o leitor decide se irá seguir as instruções indicadas pelo autor, já que textos com função predominantemente instrutiva, como as bulas de medicamentos, são "uma oferta de atuação para o ouvinte ou para o leitor [...] e, por isso, agem como performativos; essa oferta de atuação é aceita de acordo com a situação e intenção do ouvinte e realizada seletivamente $" 4$ (FANDRYCH 2011: 31).

Assim como não é possível dizer quem são os reais autores do texto de uma bula, também fica indefinido o momento da produção do texto; algumas causas podem ser citadas, como, por exemplo: o texto deve ser alterado caso alguma informação mude; pode haver atualizações de informação à medida que o medicamento é aprimorado; adequações do texto e/ou formatação podem ocorrer em caso de mudanças nas prescrições jurídicas do país. A respeito da recepção, por se tratar de um texto que acompanha determinado produto, conclui-se que a leitura de uma bula se dará após a compra do medicamento e com a presença dele - teoricamente, uma leitura desvinculada do produto não teria sentido. $\mathrm{O}$ consumidor/paciente poderá recorrer à bula quando buscar informações sobre o medicamento adquirido e respostas para suas dúvidas acerca do modo de usá-lo.

4 ein Handlungsangebot an den Hörer bzw. Leser [...] und so handlungspräformierend wirken; dieses Handlungsangebot wird je nach Situation und Intention des Hörers angenommen und (selektiv) rezipiert

Pandaemonium, São Paulo, v. 15, n. 20, Dez. /2012, p. 224-261 - www.fflch.usp.br/dlm/alemao/pandaemoniumgermanicum 


\section{Cintra, A. D - Bulas de medicamentos}

Tanto na produção quanto na recepção, autor e leitor estão temporal e espacialmente separados, o que é característico de textos escritos. Da mesma forma que pouco se sabe a respeito do aspecto temporal da recepção e produção do texto das bulas, sobre o espaço desses dois momentos, o que há também são apenas deduções: a produção pode ocorrer na empresa farmacêutica onde o medicamento é fabricado ou em uma agência/departamento de redação técnica; já a recepção ou leitura do texto pode ser realizada em qualquer lugar quando se tem o medicamento. Por fim, é conveniente lembrar que o gênero textual bula de medicamento está diretamente relacionado a prescrições jurídicas que determinam, sobretudo, o formato, a organização e a obrigatoriedade de certas informações e, dessa forma, configuram-se como um fator importante na constituição do texto. Sendo assim, é muito provável que a estrutura rígida do gênero apresente variações de acordo com o país e suas respectivas leis, fato que justifica a inclusão desse aspecto nos estudos anteriores à análise linguístico-textual.

\subsection{Contexto I: bulas alemãs}

A Alemanha é considerada mundialmente uma importante referência no setor químico. O crescimento industrial do país, no final do século XIX, acelerou o desenvolvimento da indústria química, que passou a concentrar as pesquisas farmacêuticas nos seus próprios laboratórios. Essa nova realidade trouxe grandes e importantes progressos para a área, como, por exemplo, a criação de patentes e, consequentemente, a produção de medicamentos em larga escala. Entretanto, até 1961 não havia leis que regulamentassem, entre outros aspectos, a produção ou os testes clínicos dos novos medicamentos, tampouco era obrigatória a disponibilização de informações básicas ao paciente a respeito do produto adquirido, ou seja, medicamentos poderiam ser vendidos sem as respectivas bulas. Todos esses fatores levaram a um dos maiores escândalos médicos nacional, senão mundial: o caso Contergan [Contergan-Affäre] (NEUBACH 2009: 38-39). 


\section{Cintra, A. D - Bulas de medicamentos}

O medicamento conhecido como Contergan foi desenvolvido pela empresa farmacêutica Grünenthal GmbH. Sua principal substância ativa, talidomida [em alemão: Thalidomid], não foi testada em grupos específicos de pacientes, como gestantes, cardíacos ou diabéticos e, como ainda não existia uma licença para a circulação dos medicamentos, a venda do Contergan foi autorizada em 1956. Já no ano seguinte, a empresa passou a distribuí-lo para o restante da Alemanha e exportá-lo para mais de 40 países, entre outros, o Brasil e, em pouco tempo, esse medicamento se tornou muito popular, inclusive entre as gestantes, por se tratar de um calmante e sonífero e também por não ser necessária a apresentação de receita médica no ato da compra. No início dos anos 1960, começaram a surgir os primeiros registros de efeitos colaterais. As principais ocorrências indicavam danos neurológicos nos pacientes que faziam uso prolongado de Contergan; a fim de minimizar tais riscos, a medida adotada pela empresa foi indicar na bula que tais danos eram reversíveis, caso a interrupção do tratamento fosse imediata, o que não ficou comprovado, como se soube mais tarde. Embora cada vez mais muitos outros prejuízos para a saúde dos pacientes eram diagnosticados, o composto não foi retirado de circulação e, apenas em novembro de 1961, a empresa Grünenthal ordenou a suspensão das vendas de Contergan, após alertas de vários especialistas de que o medicamento poderia interferir no desenvolvimento do feto em gestantes. Entretanto, tal medida foi adotada tardiamente, pois entre 1958 e 1962, somente na Alemanha, cerca de 4.000 crianças nasceram com algum tipo de má formação, das quais apenas 2.800 sobreviveram (KIRK 1998: s.l.).

Entre as possíveis causas de tal situação podem ser citadas a falta de determinações jurídicas ou exigências para produção e distribuição dos medicamentos, ausência de controle de qualidade e segurança e lacunas nas leis alemãs a respeito de uma regulamentação para medicamentos em todo o país. A primeira lei para a circulação de medicamentos entrou em vigor apenas em 1961 [Arzneimittelgesetz ou AMG], que, segundo NEUBACH (2009: 39), não foi criada em reação ao caso Contergan, mas sim, como parte do processo para a implantação de um mercado comum de livre circulação de produtos na Comunidade Econômica Europeia [Europäische Wirtschaftsgemeinschaft ou EWG]. A inclusão das bulas nas embalagens dos medicamentos passou a ser obrigatória em 1978, quando entraram em 


\section{Cintra, A. D - Bulas de medicamentos}

vigor alterações na $A M G$, de 24/08/1976. Contudo, dessa vez ainda não foram definidas quais informações deveriam constar obrigatoriamente nas bulas.

Em 1987, foi determinada a separação das informações em dois tipos de bula [Zweites Gesetz zur Änderung des Arzneimittelgesetzes], sendo uma para o paciente e outra para o profissional de saúde. A justificativa legal admite que "a bula de medicamento só consegue atingir seu objetivo se estiver escrita em uma linguagem compreensível para o paciente e não estiver sobrecarregada de informações técnicas e difíceis para ele" (CZETTRITZ apud NeUBACH 2009: 43).

Um dos momentos mais importantes da adequação desse documento ao público em geral ocorreu em 1992 com uma diretiva da União Europeia (CCE/27/92) a respeito das embalagens e bulas dos medicamentos. Foram regulamentados, entre outros pontos, as informações obrigatórias e suas respectivas ordens, o uso de desenhos e gráficos, além do tipo de linguagem a ser empregada. Já em 1998, a Comissão Europeia publicou o Guideline on the Readability of the Label and Package Leaflet of Medicinal Products for Human Use, um guia com sugestões e dicas para melhorar a legibilidade e compreensibilidade das bulas. As principais propostas incluem: utilização de linguagem simples e cotidiana para veicular as informações aos pacientes, substituição dos termos técnicos por seus correspondentes no vocabulário de uso comum e emprego de um estilo ativo de escrita que fale diretamente ao leitor, como por exemplo, subtítulos em forma de perguntas. Tantos esforços justificam-se quando resultam em um texto que permita ao usuário ser capaz de ponderar a automedicação e reconhecer os limites da mesma, prever os resultados esperados do tratamento e até mesmo administrar os riscos de efeitos colaterais indesejáveis.

Porém, mesmo após várias alterações na legislação nacional e europeia na tentativa de aproximar o texto da bula do paciente, ainda há registros de problemas durante a leitura. BERG-SCHMIDT (2003: 3) relata, por exemplo, que as maiores dificuldades para os leitores são interpretar o texto apresentado e lidar com muitas informações ao mesmo tempo.

5 Die Packungsbeilage kann ihre Aufgabe nur erfüllen, wenn sie in einer für den Patienten verständlichen Sprache abgefasst ist und nicht mit fachlichen für ihn unverständlichen Informationen überladen wird. 


\section{Cintra, A. D - Bulas de medicamentos}

\subsection{Contexto II: bulas brasileiras}

No Brasil, as bulas são o principal material informativo fornecido aos consumidores de medicamentos, assumindo um papel fundamental na promoção do uso racional, no processo de cumprimento ao tratamento medicamentoso e no alerta sobre os riscos da automedicação, por exemplo (VOLPATO 2009: 310).

A obrigatoriedade da inclusão da bula em todos os medicamentos produzidos e comercializados no Brasil foi estabelecida a partir da Portaria $\mathrm{n}^{\circ} 110$ da antiga Secretaria de Vigilância Sanitária, em 10 de março de 1997. Entretanto, até o momento da criação do Ministério da Saúde, em 1953, qualquer modificação na estrutura desse material ou determinação legal era tratada em legislação não específica, ou seja, por meio de decretos. O primeiro regulamento específico para bulas ocorreu apenas em 1959, quando foi definida a ordem dos itens e regulamentada a apresentação e o exame de rótulos e textos (Portaria $\mathrm{n}^{\circ}$ 49). Em 1977, no Decreto 79.094, descrevem-se pela primeira vez regras para bulas e materiais impressos dos produtos de interesse sanitário, com o intuito de favorecer a fácil leitura visual por meio de um tamanho mínimo de letra e uma linguagem acessível. Essa preocupação em tornar a bula um documento compreensível foi manifestada muitas vezes depois, por exemplo, quando institui-se um roteiro ou modelo padrão para o texto da bula (Portaria $\mathrm{n}^{\circ}$ 65, de 28 de dezembro de 1984) com itens de informação obrigatória, um texto padrão que deveria ser reproduzido e a divisão das informações entre identificação do produto, informação ao paciente, informação técnica e dizeres legais, sendo que essa última medida permanece até os dias de hoje.

A Anvisa - Agência Nacional de Vigilância Sanitária - foi criada apenas em 1999. Pela primeira vez, o Brasil passou a ter uma entidade pública com independência administrativa e autonomia financeira para cuidar da legislação referente às bulas de medicamentos. A principal tarefa desse órgão é "analisar e aprovar o material informativo produzido pela indústria farmacêutica antes de sua comercialização" (CALDEIRA, 2008: 737738). Com a criação da Anvisa, a legislação específica para bulas foi revisada, reformulada e 


\section{Cintra, A. D - Bulas de medicamentos}

publicada em 2003 (Resolução $\operatorname{RDC}^{6} \mathrm{n}^{\circ}$ 140, de 29 de maio de 2003). As medidas mais significativas em prol da facilidade da leitura foram: divisão da bula em duas, sendo uma para o paciente e outra para o profissional de saúde e o estabelecimento da organização do texto em forma de perguntas e respostas, criando uma espécie de diálogo entre a bula e o consumidor. Posteriormente, outras providências foram tomadas com o objetivo de tornar esse material mais compreensível e acessível, como por exemplo, disponibilização de bulaspadrão para cada grupo de medicamentos genéricos e de princípio ativo, publicação oficial dos textos no Bulário Eletrônico da Anvisa, atualização das informações em comparação com bulas de outros países e aumento do tamanho mínimo da letra para 1,5 mm.

Entretanto, apesar dos esforços dispensados, as bulas brasileiras ainda são alvo de muitas críticas, relacionadas, sobretudo, à qualidade do texto, à disposição textual e à linguagem utilizada. GONÇALVES ET AL. (2002: 33) alertam para o problema da inadequação do conteúdo das bulas de acordo com a legislação e a literatura científica; segundo os autores, muitas bulas apresentam um excesso de dados não relevantes, deixando de priorizar outros muito importantes para o consumidor, como cuidados de armazenamento, ação esperada ou administração do medicamento. Contudo, a linguagem empregada na escrita do documento é, supostamente, a maior dificuldade para a compreensão do texto; entre os problemas mais frequentes estão: erros de ortografia, erros de tradução, emprego de termos técnicos ou em língua estrangeira.

A legislação tenta amenizar o problema recorrendo, principalmente, à formatação, diagramação e reorganização do conteúdo. Com a finalidade de apresentar informações mais claras, objetivas e padronizadas, a mais recente resolução da Anvisa (RDC n 47, de 09 de setembro de 2009) determinou algumas alterações importantes e essas mudanças são o resultado de uma rigorosa revisão das bulas que ocorria desde 2008, devendo ser incorporadas pelas farmacêuticas até o final de 2011. Entre as principais novidades de formatação estão: fonte Times New Roman no corpo do texto; tamanho mínimo de 10 pontos para a letra; caixa alta e negrito apenas para destacar perguntas e itens; texto sublinhado ou itálico para nomes científicos e impressão em cor preta e papel não translúcido. Já mudanças

\footnotetext{
6 Resolução de Diretoria Colegiada
} 


\section{Cintra, A. D - Bulas de medicamentos}

relativas ao conteúdo incluem, primeiramente, a manutenção de algumas propostas da RDC $\mathrm{n}^{\circ}$ 140/03, como a separação de bulas para pacientes e bulas para profissionais de saúde, conteúdo organizado em forma de perguntas e respostas na bula do paciente e a adequação de linguagem e conteúdo em cada tipo de bula. As inovações abrangem a organização das informações conforme afinidade de conteúdo (itens afins); detalhamento maior na norma das informações exigidas em cada item e informações mais objetivas que contemplem as reais necessidades de cada público.

\section{Coleta do corpus e metodologia de análise}

Dado que o objetivo geral do presente trabalho é comparar textos de duas línguas diferentes, durante a seleção do corpus, levou-se em consideração que esses textos fossem comparáveis, ou seja, que pertencessem ao mesmo gênero textual e que mantivessem as mesmas funções comunicativas (BHATIA 1993 apud SCHWEIGER 2011: 81). Visto isso, foram estabelecidos critérios de seleção do corpus, de acordo com a especificidade do gênero textual escolhido (a bula de medicamentos).

A princípio, determinou-se que comporiam o corpus bulas de medicamentos análogos entre si, ou seja, pertencentes à mesma categoria e fabricados por farmacêuticas alemãs e brasileiras nos próprios países, respectivamente, não incluindo medicamentos importados ou fabricados fora do país de origem da farmacêutica, nem bulas publicadas na Internet, já que muitas vezes essas não correspondem às que são comercializadas. Evitou-se, porém, analisar bulas de farmacêuticas alemãs comercializadas no Brasil para evitar possíveis interferências de tradução. A categoria de medicamentos escolhida foi a dos analgésicos, por serem estes, de modo geral, muito consumidos pela população, já que algumas de suas principais funções são: alívio da dor, redução da febre e alívio dos sintomas da gripe. Outro critério considerado importante e adotado em seguida foi a venda livre desses medicamentos, pois se uma prescrição médica não é necessária no ato da compra, isso significa que provavelmente o paciente não terá o respaldo de um profissional da saúde 


\section{Cintra, A. D - Bulas de medicamentos}

para administrar o medicamento, o que aumenta a importância da compreensão das informações contidas na bula. Um terceiro critério de seleção foi criado a fim de tornar as bulas ainda mais comparáveis, e esse critério é o princípio ativo, ou seja, não era suficiente apenas delimitar o tipo de medicamento, eles deveriam ter também a mesma substância principal. Na extensa categoria dos analgésicos, optou-se por analisar os com princípio ativo paracetamol (preferencialmente sem composição com outras substâncias), por serem esses muito consumidos e a grande maioria dos laboratórios possuir pelo menos um medicamento à base de paracetamol.

Definidos os três critérios de seleção do corpus, foi iniciada a coleta do material. Ao todo, o corpus deste trabalho é composto por 20 bulas de medicamentos, sendo dez bulas alemãs e dez bulas brasileiras.

Quanto à metodologia adotada para a análise, foi realizado um estudo descritivo, no qual o objeto é investigado no seu contexto histórico e jurídico-social e temporal. No que diz respeito à análise de um gênero textual específico, como nesta pesquisa, foram combinadas várias dimensões descritivas a fim de abordar, na medida do possível, o máximo de aspectos que compõem esse texto. Entre elas, estão principalmente: a situação comunicativa, a função textual (apresentados no item 2), o âmbito temático-estrutural (correspondente à macroestrutura) e o âmbito gramatical (correspondente à microestrutura).

ADAMZIK (2009: 241) propõe esses dois níveis de análise dos textos, que atualmente estão presentes nos principais estudos contrastivos com textos, que são os níveis da macroestrutura e da microestrutura. De modo geral, pode-se dizer que a macroestrutura de um texto compreende, principalmente, esse objeto como um todo, inclusive sua função ilocucional, já que está se tratando de gêneros inseridos no processo de comunicação; a microestrutura abrange os constituintes do texto, como, por exemplo, características lexicais, semânticas e pragmáticas num nível mais pontual. Essa abordagem dos dados está orientada, de modo contrastivo, do macro para o micro, ou seja, partirá do texto visto como objeto unitário e dirigir-se-á às microestruturas do mesmo, sempre comparando o par linguístico em questão. ECKKRAMMER (2009: 292) justifica tal proposta argumentando que "uma 


\section{Cintra, A. D - Bulas de medicamentos}

análise das microunidades faz sentido apenas depois que se tenha formado uma ideia do que seja a estrutura básica com suas sequências temáticas e sua ordem prototípica”.

\section{Análise Macroestrutural}

A análise macroestrutural comporta dois grandes momentos. O primeiro deles trata da delimitação temática do texto analisado, ou seja, investigar qual assunto é abordado por ele. Alguns aspectos que podem auxiliar na identificação do tema são: léxico, título, subtítulo e conteúdo. O segundo grande momento é a descrição do desenvolvimento do tema ou estratégias de composição textual, que podem ser, basicamente, descritiva, narrativa, explicativa, argumentativa ou instrutiva. Esses seis tipos de estratégias textuais são possibilidades que podem ser combinadas, mas o essencial é descrever a forma predominante no gênero, pois é ela que determina a estrutura textual. Além disso, ela exerce muita influência sobre as escolhas dos meios linguísticos, como por exemplo, tempo verbal, tipo de ligação entre as frases, entre outras.

\subsection{Macroestrutura das bulas alemãs}

$\mathrm{Na}$ análise das dez bulas alemãs que compõem o corpus deste trabalho, foi possível identificar, invariavelmente, dez partes principais do texto: 1) Título; 2) Identificação do medicamento; 3) Sugestão/ aconselhamento de leitura; 4) Índice; 5) Informações sobre a classe terapêutica e indicações; 6) Informações antes da ingestão do medicamento; 7) Instruções de uso; 8) Efeitos colaterais; 9) Informações sobre armazenamento; 10) Outras informações e 11) Desejo de melhoras (opcional).

Observou-se que, tanto a disposição dos itens quanto sua nomeação, são idênticas nas dez bulas analisadas, o que pode ser explicado por meio da Diretiva $\mathrm{n}^{\circ} 27$ da Comunidade Europeia (2004/27/CE), promulgada no dia 31 de março de 2004 e 
Cintra, A. D - Bulas de medicamentos

implementada na Alemanha em setembro de 2005 através da alteração da lei [Arzneimittelgesetz - AMG] acerca do conteúdo e organização das informações das bulas para que tais medicamentos tivessem sua comercialização e circulação aceitas em toda a União Europeia. Segundo a Diretiva 2004/27/CE, há sete itens obrigatórios que devem estar presentes em todas as bulas de medicamentos europeus e, portanto, alemães:
a) Identificação do medicamento;
b) Indicações terapêuticas;
c) Enumeração das informações necessárias antes da tomada do medicamento (contra- indicações, precauções, interações medicamentosas e advertências);
d) Habituais instruções necessárias à sua boa utilização (posologia, duração do tratamento, frequência de administração etc.);
e) Descrição das reações adversas que podem manifestar-se quando da utilização normal do medicamento e, se necessário, medidas a tomar;
f) Prazo de validade, também inscrito no rótulo;
g) Data em que o folheto informativo foi revisto pela última vez. ${ }^{7}$

No texto da lei alemã para a circulação de medicamentos [Arzneimittelgesetz $A M G$ ], que em dezembro de 2005 incorporou as determinações da Diretiva 2004/27/CE, consta o seguinte:

No âmbito de validade desta legislação, somente medicamentos que contenham uma bula com o título "Bula de Medicamento", portadora das seguintes informações na presente sequência e escrita em língua alemã compreensível, letra legível e em consonância com as informações segundo Artigo 11a podem entrar em circulação $[\ldots] .^{8}$

\footnotetext{
7 Adaptado da Diretiva 2004/27/CE do Parlamento Europeu e do Conselho de 31 de março de 2004. Uma versão em língua alemã desta Diretiva está disponível em <http://ec.europa.eu/health/files/eudralex/vol1/dir_2004_27/dir_2004_27_de.pdf>.

8 Fertigarzneimittel [...] dürfen im Geltungsbereich dieses Gesetzes nur mit einer Packungsbeilage in den Verkehr gebracht werden, die die Überschrift „Gebrauchsinformation“ trägt sowie folgende Angaben in der nachstehenden Reihenfolge allgemein verständlich in deutscher Sprache, in gut lesbarer Schrift und in Übereinstimmung mit den Angaben nach $\S 11 \mathrm{a}$ enthalten muss [...].
} 


\section{Cintra, A. D - Bulas de medicamentos}

Com isso, a partir de 2005, todas as bulas que acompanharem medicamentos produzidos na Alemanha devem conter, obrigatoriamente, essas sete informações em determinada ordem, o que foi verificado no corpus analisado por esse trabalho.

Tendo em vista ainda o trecho citado da $A M G$ de 2005, o título do texto (item 1) também é um elemento obrigatório nas bulas alemãs, embora não tenha sido indicado como tal pela Diretiva 2004/27/CE. Já os itens 3 e 4 da macroestrutura apresentada (Sugestão/ Aconselhamento de leitura e Índice) não são mencionados nem pela lei alemã nem pela legislação da União Europeia, mas sim, pelo Guideline on the Readability of the Label and Package Leaflet of Medicinal Products for Human Use, publicado pela Comissão Europeia. A respeito desses dois pontos, Neubach (2009: 109) alerta para o fato de que tanto um quanto outro não são elementos obrigatórios segundo as leis que regem a configuração das bulas na Europa e na Alemanha e, portanto, sua ausência não seria vista como uma infração às mesmas. Por fim, o item de número 11 (Desejo de melhoras) foi o único considerado opcional por não ser mencionado como obrigatório em nenhum dos documentos citados ( $A M G$, Diretiva CE/27/2004 ou Guidelines), ficando sua inserção a critério do laboratório farmacêutico.

Os quatro primeiros itens da macroestrutura das bulas alemãs (Título, Identificação do medicamento, Sugestão/ Aconselhamento de leitura e Índice) podem ser considerados itens pré-textuais, uma vez que antecedem as informações principais a respeito do uso do medicamento, ou seja, as instruções propriamente. Desses, apenas o título e a identificação do medicamento são obrigatórios, segundo a Diretiva 2004/27/CE e a $A M G$ de 2005, respectivamente, já que sugestão/ aconselhamento de leitura e índice são apenas recomendações do guia de redação para melhorar a legibilidade das bulas de medicamentos. O título Gebrauchsinformation: Information für den Anwender [Bula de medicamento: Informações para o paciente] tem a função de indicar brevemente ao leitor que tipo de texto é esse que acompanha o medicamento adquirido e qual a sua função. Em seguida, a identificação do medicamento é um dos primeiros itens da ordem estipulada, até mesmo antes das instruções, porque deve apresentar as principais características do produto ao 


\section{Cintra, A. D - Bulas de medicamentos}

consumidor, como por exemplo, nome comercial e forma de apresentação farmacêutica ${ }^{9}$ do medicamento, seu princípio ativo ${ }^{10}$, muitas vezes o grupo ao qual se destina etc. A sugestão/ aconselhamento de leitura, terceiro item do texto, chama a atenção do leitor para a importância da leitura da bula de medicamento, aconselhando-o a assim fazê-lo; além disso, o campo alerta para o fato de que um medicamento de venda livre, como é o caso dos analgésicos, deve ser ingerido de acordo com as instruções previstas na bula e também que, em situações extraordinárias, como piora do quadro clínico ou aparecimento de efeitos colaterais que não sejam os mencionados na bula, é necessário procurar um médico. $\mathrm{O}$ aconselhamento de leitura, presente atualmente na maioria das bulas alemãs, foi adaptado do modelo em inglês fornecido pelo guia de redação de bulas. O último elemento pré-textual que antecede as informações principais da bula alemã é uma espécie de índice que elenca brevemente os próximos tópicos a serem abordados no texto em sua respectiva ordem. Assim como o aconselhamento de leitura, o índice faz parte das estratégias propostas pelo guia, na expectativa de fazer com que as bulas dos países participantes da União Europeia sejam mais acessíveis ao paciente/consumidor.

A partir do item 5, inicia-se na bula alemã a parte das instruções efetivamente. Os cinco tópicos seguintes, portanto 5, 6, 7, 8 e 9, trazem informações mais específicas a respeito do tratamento com o fármaco adquirido. São, principalmente, esses itens que tiveram seu conteúdo planejado pela Diretiva 2004/27/CE e, na sequência, determinado pela AMG de 2005 e, por isso, tanto o teor das informações quanto sua ordem, estão rigorosamente estabelecidas. Sendo assim, o trecho começa situando o medicamento em uma classe terapêutica, classificando-o como um analgésico, no caso das bulas analisadas, e elencando as indicações de tal, ou seja, apontando em quais situações clínicas o produto terá o efeito desejado - febre alta e dor de cabeça, por exemplo, [Was ist und wofür wird es angewendet?]. Em seguida, são descritas uma série de informações que o paciente/ consumidor precisa saber ainda antes de iniciar o tratamento e, assim, ingerir o medicamento com consciência [Was müssen Sie vor der Einnahme von beachten?]; segundo

\footnotetext{
${ }^{9}$ Se em comprimidos ou solução oral.
} 


\section{Cintra, A. D - Bulas de medicamentos}

a AMG, essas informações devem ser as contraindicações, precauções e os cuidados necessários relacionados à interação desse remédio com outros que, eventualmente, também estejam sendo administrados no mesmo período. Desses cinco itens da parte principal do texto da bula, o que traz instruções mais explicitamente é o de número 7 [Wie ist einzunehmen?]; essas instruções dizem respeito à administração do medicamento e, sendo assim, abordam tópicos como dosagem adequada, modo de ingestão do remédio - por exemplo, se antes ou após as refeições, em jejum, com ou sem água etc. -, frequência e duração do tratamento, cuidados para grupos de pacientes com necessidades especiais (idosos, crianças abaixo do peso, entre outros) e procedimentos em casos esquecimento ou ingestão de uma dosagem maior do que a recomendada (superdosagem). O item seguinte, número 8, trata, especificamente, dos efeitos colaterais que podem surgir durante o tratamento com o fármaco em questão, além de aconselhar medidas para anular tal efeito, de acordo com a AMG [Welche Nebenwirkungen sind möglich?]; vale ressaltar que todas as reações indesejadas listadas na bula aparecem acompanhadas de um dado que indica a frequência com que ocorre, por exemplo, 'muito frequente', 'frequente', 'ocasional', 'raro', 'muito raro' ou 'desconhecido'. Finalmente, encerrando a parte das instruções, o item 9 deve indicar ao paciente a que condições de armazenamento o fármaco deve ser submetido [Wie ist aufzubewahren?], ou seja, em ambiente seco e arejado, na própria embalagem, longe do alcance de crianças, entre outras. Outras informações obrigatórias determinadas pela Diretiva 2004/27/CE e pela AMG, como forma de apresentação e características físicas do medicamento, composição química, nome e endereço do laboratório farmacêutico e/ou da distribuidora e data da última atualização da bula, são apresentadas no que corresponde ao item 10 da macroestrutura, sob o título de Outras informações [Weitere Informationen].

A partir do estudo da macroestrutura do texto das bulas alemãs, além do conteúdo e da organização deste, foi possível observar outros detalhes igualmente relevantes. Nota-se que os dez principais itens da bula alemã são sempre identificados com títulos em forma de

\footnotetext{
${ }^{10}$ Substância principal da composição química do medicamento que irá agir no organismo e fazer com que o efeito desejado seja obtido.
} 


\section{Cintra, A. D - Bulas de medicamentos}

perguntas, por exemplo, Welche Nebenwirkungen sind möglich? [Quais são os possíveis efeitos colaterais possíveis?], ao invés de simplesmente 'Efeitos Colaterais'. A opção por perguntas nos títulos das seções principais é uma sugestão do guia para redação de bulas; o Bundesinstitut für Arzneimittel und Medizinprodukte [Instituto Nacional para Medicamentos e Produtos Medicinais], um órgão ligado ao Bundesgesundheitsamt [Agência Federal da Saúde] que fez a adaptação do modelo original em inglês estabelecido pelo guia para a língua alemã, justificou tal medida da seguinte forma: "As informações da bula de medicamento devem ser veiculadas de forma que o paciente receba, na medida do possível, instruções concretas a partir do texto" (SCHWEIM, 2002: 3) ${ }^{11}$. Neubach (2009: 111) acrescenta ainda que outra vantagem da formulação dos títulos principais como perguntas, além do estabelecimento de uma situação concreta de instrução, é a forma direta com a qual o leitor/paciente é tratado, o que, segundo o guia, influencia positivamente a legibilidade do texto da bula.

Outro aspecto que chama atenção na macroestrutura das bulas alemãs é a utilização de tabelas como um recurso gráfico e visual para trazer informações. Na análise das dez bulas deste trabalho, foi possível identificar que todas possuem uma tabela para complementar os itens 7 e 8 (instruções de uso e efeitos colaterais), respectivamente. No primeiro, a tabela auxilia o leitor com relação à dosagem de paracetamol a ser administrada para crianças abaixo do peso (grupo de pacientes com necessidades especiais), uma vez que tal fator depende de duas variáveis, sendo elas peso e idade; já no item 8, a tabela funciona como uma espécie de legenda para a frequência com que os efeitos colaterais mencionados ocorrem, indicando em números os termos empregados.

\footnotetext{
${ }^{11}$ Die Informationen der Packungsbeilage sollen so abgefasst werden, dass der Patient aus den Angaben möglichst konkrete Handlungsanweisungen erhält.
} 


\section{Cintra, A. D - Bulas de medicamentos}

\subsection{Macroestrutura das bulas brasileiras}

Após a análise macroestrutural das dez bulas brasileiras que compõem o corpus deste trabalho, foi possível identificar que as informações do texto estão divididas em quatro partes principais: Identificação do medicamento, Informações ao paciente, Informações técnicas aos profissionais de saúde e Dizeres legais.

Desde a criação da Anvisa, muitas medidas foram tomadas para tornar a bula um instrumento de informação cada vez mais eficiente, sobretudo para o paciente. Entre as regulamentações mais importantes estão RDC $n^{\circ} 140 / 03$ e $\operatorname{RDC~} n^{\circ} 47 / 09$, as quais se ocuparam da reformulação do conteúdo e da forma das bulas brasileiras, respectivamente.

Segundo o Art. $2^{\circ}$ da $\operatorname{RDC~n}{ }^{\circ} 140 / 03$, as bulas de todos os medicamentos que são comercializados no Brasil devem ter incorporados ao seu texto os itens de identificação do medicamento, informações aos pacientes, informações técnicas aos profissionais de saúde e dizeres legais. Em 2009, com o objetivo de aprimorar a proposta da RDC n ${ }^{\circ} 47 / 03$, a RDC $\mathrm{n}^{\circ} 47$ determinou que as informações aos pacientes e as informações técnicas deveriam ser separadas, criando, dessa forma, bulas distintas para os pacientes e para os profissionais de saúde. Sendo assim, ficou estipulado, segundo o Art. $6^{\circ}$ da RDC 47/09, que "as bulas para o paciente devem conter os itens relativos às partes Identificação do Medicamento, Informações ao Paciente e Dizeres Legais, previstos no Anexo I desta resolução [...]" (2009: 6). Conforme apresentado na macroestrutura identificada por meio da análise de dez bulas brasileiras, percebe-se que todas contêm essas partes obrigatórias, na mesma ordem determinada pela última resolução.

De acordo com o Anexo I da RDC n 47/09, o item de identificação do medicamento deve abordar, na sequência, principalmente as informações a respeito da forma de apresentação farmacêutica do remédio em questão (se em comprimido, cápsula ou solução oral, por exemplo), a via de administração, o grupo ao qual se destina e a composição química, além do nome comercial ou marca do medicamento e a denominação do princípio ativo logo no início da bula. Entretanto, apesar da regulamentação, nem todas as bulas 


\section{Cintra, A. D - Bulas de medicamentos}

possuem essas informações, conforme foi possível constatar a partir da análise do corpus desta pesquisa; por exemplo, algumas não delimitam o grupo de pacientes ao qual o fármaco é aconselhado ou mesmo não indicam claramente qual é o princípio ativo da fórmula, ao passo que outras incluem, juntamente com essas informações obrigatórias, outros dados adicionais, como outras formas de apresentação farmacêutica possíveis e a lei do medicamento genérico, se for o caso.

No item de informações ao paciente, as bulas brasileiras devem conter, necessariamente e nessa ordem, os seguintes tópicos, tendo em vista a RDC $\mathrm{n}^{\circ}$ 47/09: descrição das indicações de uso do medicamento; descrição do modo de ação do fármaco no organismo; descrição das contra-indicações; advertências e precauções para o uso adequado; instruções a respeito do modo de armazenamento do produto (inclusive mencionando a data de validade); orientações acerca do modo adequado de preparo e/ou manuseio do medicamento; procedimentos em caso de esquecimento; descrição das reações adversas; procedimentos em caso de ingestão de uma dosagem maior que a recomendada (superdose). O que se percebe com a análise macroestrutural das mesmas é que, assim como no item de identificação do medicamento, há informações obrigatórias que não são contempladas em todas as bulas, por exemplo, o modo de armazenamento e os procedimentos em caso de esquecimento. Em contrapartida, outras bulas analisadas passam a impressão de serem mais detalhadas ou mais completas, isso porque algumas informações que pertencem aos tópicos acima listados surgem sob a designação de um novo subtítulo, criando essa ilusão; por exemplo, indicar a classe terapêutica, ou seja, a que grupo de medicamento o produto pertence (se analgésico, antitérmico, antibiótico etc.) já é um dado que estaria incorporado à unidade de título 'Indicações', porém, em alguns casos, pode surgir como um assunto tratado a parte.

Com relação às informações técnicas para os profissionais de saúde, não se pode deixar de notar que oito delas, ou seja, a maioria, ainda inclui essa parte conforme a legislação antiga, mesmo tendo sido estabelecido pela nova resolução que esse item deveria ser eliminado das bulas que acompanham os medicamentos comercializados. Sabe-se que a Anvisa concedeu um período de transição, de setembro de 2009 a dezembro de 2011, para 


\section{Cintra, A. D - Bulas de medicamentos}

que os laboratórios farmacêuticos pudessem se adequar a essa nova regra e elaborar bulas diferentes para informações ao paciente e informações técnicas, entretanto, como a análise do presente trabalho mostrou, ainda há algumas bulas organizadas segundo a RDC 140/03 em circulação, embora tenham sido coletadas no período de agosto a outubro de 2011. Os subitens da parte de informações técnicas não foram analisados detalhadamente, uma vez que o foco desta pesquisa restringiu-se às bulas do paciente ou às informações a ele destinadas.

Por fim, a seção de dizeres legais foi identificada nas dez bulas analisadas por este trabalho. Contudo, chama a atenção que apenas três delas traziam essa seção sob o título 'Dizeres Legais', conforme determinado pela RDC 47/09, já as demais incorporam tais informações sem o título logo após as informações ao paciente (ou informações técnicas aos profissionais de saúde, no caso das bulas em consonância ainda com a legislação anterior). Com relação ao conteúdo obrigatório desse item, é necessário que o laboratório farmacêutico informe ao consumidor/paciente a respeito dos seguintes tópicos: número do registro no Ministério da Saúde (MS), nome e número de registro no Conselho Regional de Farmácia do responsável técnico da empresa, razão social e endereço da empresa fabricante, distribuidora, importadora, se for o caso, telefone do Serviço de Atendimento ao Consumidor (SAC), data de aprovação da bula pela Anvisa e data de sua última atualização. Apenas as datas de aprovação pela Anvisa e última atualização da bula não foram contempladas nos textos de oito das dez bulas brasileiras analisadas; talvez essa ausência possa ser explicada novamente a partir da proposta de aprimoramento e atualização da RDC 140/03, pois antes da mudança os itens obrigatórios para essa seção não incluíam tais datas.

A respeito da ordem dos subitens nos tópicos principais, constatou-se, após a análise do corpus brasileiro, que a maioria das bulas verificadas - nove das dez - não seguem exatamente a sequência determinada pela RDC 47/09 e apresentada no Anexo I da mesma, fazendo que com exista muita variação entre elas e também com relação ao esperado pela lei. O Art. $6^{\circ}$ da regulamentação, já citado neste trabalho, menciona com clareza que os textos devem seguir "a ordem das partes e itens de bulas estabelecidos" pelo Anexo I, sendo as partes Identificação do medicamento, Informações ao paciente e Dizeres Legais e os 


\section{Cintra, A. D - Bulas de medicamentos}

itens, suas respectivas informações específicas. A partir daí, conclui-se que as partes obedecem, em todas as bulas analisadas, a ordem preestabelecida, já os seus itens, não o fazem.

Da mesma maneira, está determinado nessa mesma regulamentação que os textos das bulas para os pacientes devem "ser organizados na forma de pergunta e resposta" (Art. $6^{\circ}, \S$ $1^{\circ}$ ). Esta é uma das novidades que a RDC 47/09 trouxe com relação à RDC 140/03, juntamente com a criação da bula para o paciente e da bula para o profissional de saúde, numa tentativa de adequar a linguagem e o conteúdo em cada tipo de bula. Com essa proposta, os títulos dos itens deveriam ser elaborados como uma pergunta, já antecipando, com isso, uma provável dúvida que o paciente possa ter ou uma situação com a qual ele poderá se deparar, por exemplo 'Indicações' - 'Para quê este medicamento é indicado?'. Entretanto, a análise macroestrutural mostrou que apenas quatro das dez bulas brasileiras que compõem o corpus já apresentam os títulos em forma de pergunta e a hipótese que melhor explica esse fato é, novamente, a de que muitas bulas ainda não foram adaptadas à nova regulamentação de 2009, mesmo tendo sido coletadas em período próximo ao prazo final estipulado pela Anvisa para que todas se adequassem à mudança (dezembro de 2011).

A respeito do uso de elementos gráficos, como tabelas e figuras, para auxiliar na interpretação de informações, nenhuma das bulas investigadas possui tal recurso, tampouco há algum parágrafo na mais recente regulamentação que indique diretrizes para seu emprego, se for o caso.

\section{Análise Microestrutural}

Tendo em vista o estudo do gênero 'bula de medicamento', foram escolhidas cinco microunidades linguísticas que estão bastante relacionadas com a função informativoinstrutiva, característica do texto das bulas, para serem analisadas contrastivamente no par linguístico em questão. 


\section{Cintra, A. D - Bulas de medicamentos}

\subsection{Formas de tratamento ao leitor}

Nas bulas da Alemanha, o texto refere-se invariavelmente ao leitor com o pronome de tratamento Sie, normalmente empregado quando não há uma relação muito próxima entre os interlocutores ou quando eles são desconhecidos entre si (ex.: Sie haben Paracetamol 500 mg Heumann, ein Arzneimittel mit dem bewährten Wirkstoff Paracetamol, enthalten). É importante destacar que três das dez bulas alemãs analisadas iniciaram alguma instrução com o vocativo 'Liebe Patientin/ Lieber Patient'.

Nas bulas brasileiras, o pronome de tratamento empregado na maior parte das vezes é 'você' e, diferentemente de Sie, no alemão, não possui qualquer conotação de formalidade, podendo ser considerado uma forma de tratamento neutra (ex. "Como ocorre com outros medicamentos, se você está grávida, planejando engravidar ou se está amamentando, consulte um profissional de saúde antes de usar Sonridor”). Entretanto, em algumas bulas brasileiras, o uso do pronome você é intercalado com formas impessoais de tratamento, (ex. "Deve-se evitar o uso de Dôrico com bebidas alcoólicas, pois pode causar danos ao fígado, assim como outros medicamentos que contenham paracetamol”).

\subsection{Associação entre termos técnicos e cotidianos}

Devido à interface que o gênero 'bula de medicamento' estabelece entre uma área de conhecimento específica e a comunicação cotidiana, o grande desafio desses textos é combinar as informações obrigatórias, provenientes das ciências médicas e farmacêuticas, com a função principal de instruir um amplo e variado público a respeito do medicamento em questão, fazendo com que esse tipo de texto se torne acessível.

A solução para esse impasse cria uma situação em que os termos específicos da medicina ou farmacêutica são associados a seus respectivos termos cotidianos, paráfrases ou exemplos para que o texto se torne compreensível a um público leigo e, ao mesmo tempo, 


\section{Cintra, A. D - Bulas de medicamentos}

não deixe de instruir e informar correta e integralmente. Essa estratégia de associação é garantida pelas leis que regulamentam as bulas de medicamentos, tanto no Brasil quanto na Alemanha. Além disso, os guias de redação de bulas de ambos os países também se referem explicitamente a essa estratégia e suas vantagens, inclusive instruindo os responsáveis pela elaboração das bulas a respeito de como as combinações ou mesmo substituições de termos podem ser feitas.

A partir das observações do corpus em alemão e em português que integraram esta pesquisa, foram identificadas duas principais organizações da estratégia de associação de termos: na primeira, o termo técnico específico é apresentado no corpo do texto e, em seguida, normalmente entre parênteses, seu respectivo termo popular, exemplo ou paráfrase; já o outro tipo de organização é, na verdade, o inverso da primeira, ou seja, as principais informações são dadas sob a forma de exemplos, paráfrases ou termos populares e o termo técnico específico é colocado entre parênteses somente após as mesmas, configurando-se, dessa maneira, como uma informação extra para o paciente e não como explicação propriamente, como no primeiro caso. Abaixo, divididas em dois grupos, estão listadas as principais combinações encontradas no corpus analisado:

\begin{tabular}{|l|l|l|l|}
\hline \multicolumn{3}{|c|}{ Específico - Comum } \\
\hline & $\begin{array}{l}\text { termo técnico - termo } \\
\text { popular }\end{array}$ & $\begin{array}{l}\text { termo técnico } \\
\text { paráfrase }\end{array}$ & $\begin{array}{l}\text { termo técnico - } \\
\text { exemplo }\end{array}$ \\
\hline bula alemã & $\begin{array}{l}\text { überempfindlich } \\
\text { (allergisch) }\end{array}$ & $\begin{array}{l}\text { maximale Tagesdosis (24 } \\
\text { Stunden) }\end{array}$ & $\begin{array}{l}\text { reichlich Flüssigkeit } \\
\text { (z. B. 1 Glas Wasser) }\end{array}$ \\
\hline bula brasileira & $\begin{array}{l}\text { solução oral } \\
\text { (gotas) }\end{array}$ & $\begin{array}{l}\text { temperatura ambiente } \\
\text { (entre 15 e 30 } 0^{\circ} \text { C) }\end{array}$ \\
\hline
\end{tabular}




\section{Cintra, A. D - Bulas de medicamentos}

\begin{tabular}{|l|l|l|}
\hline & \multicolumn{2}{|c|}{ Comum - Específico } \\
\hline & termo popular - termo técnico & paráfrase - termo técnico \\
\hline bula alemã & $\begin{array}{l}\text { schmerzstillendes Arzneimittel } \\
\text { (Analgetikum) }\end{array}$ & $\begin{array}{l}\text { Verengung der Atemwege (Analgetika- } \\
\text { Asthma) }\end{array}$ \\
\hline bula brasileira & açúcar (amido) & $\begin{array}{l}\text { mais do que a dose recomendada } \\
\text { (superdose) }\end{array}$ \\
\hline
\end{tabular}

Nota-se que há muitas correspondências dessa mesma estratégia entre as bulas alemãs e as bulas brasileiras, isto é, muitas possibilidades de combinação são usadas em uma e também em outra. Entretanto, nessa análise, chama a atenção que as bulas alemãs empregam a estratégia mais vezes, dado que a quantidade de exemplos encontrados em seu texto foi ligeiramente maior do que nas bulas brasileiras; além disso, também foi possível observar que, no corpus alemão, há um tipo de combinação a mais que não foi identificado em momento algum no corpus brasileiro. Em estudo análogo realizado em 2010, HERGET; ALEGRE chegaram a uma conclusão semelhante após analisar contrastivamente a associação entre termos técnicos e comuns em bulas alemãs e portuguesas.

Segundo as autoras, esse fato deve-se à própria característica da gênese das línguas, uma vez que, em alemão, há uma distância maior entre uma palavra técnica da medicina ou da farmacêutica e sua forma comum, daí a necessidade de explicações, porém, ao mesmo tempo, na língua alemã há mais possibilidades de duplicação de um determinado termo justamente por causa dessa distância. Sendo assim, o texto da bula alemã pode empregar tanto a forma erudita da palavra, com origem no latim ou no grego, quanto a sua forma popular correspondente, com origem na própria língua alemã, para esclarecê-lo, como é o caso do lexema 'diabetes', cuja forma erudita é Diabetes Mellitus e popular Zuckerkrankheit, no alemão.

Já na língua portuguesa (seja ela de Portugal ou do Brasil), as possibilidades de diferenciação são menores, visto que esse idioma é proveniente do latim e a maioria dos termos específicos da medicina e da farmacêutica também, ou seja, há muita semelhança entre a forma erudita e a forma popular, fazendo com que a necessidade de esclarecimento, 


\section{Cintra, A. D - Bulas de medicamentos}

consequentemente, também diminua, pois elas podem ser facilmente reconhecidas. Neste caso, nomes de doenças, sintomas, substâncias ou procedimentos médicos muito comuns, embora pertencentes a uma linguagem técnica e específica, tendem a ser incorporados nessa mesma forma pela linguagem cotidiana, como por exemplo 'taquicardia', 'náusea', 'diurético', 'diabetes', 'vasodilatação', eliminando também o uso de um segundo termo, paráfrase ou explicação no texto da bula em português (cf. SiLVA ET AL., 2000: 187). Na situação oposta à relatada anteriormente, também não foram utilizadas correspondências em língua portuguesa (Brasil), ou seja, quando o termo cotidiano é utilizado muito frequentemente na linguagem técnica ao invés de seu equivalente erudito, por exemplo, 'dor de cabeça' substituindo 'cefaleia', 'dor de dente' no lugar de 'odontalgia' e 'amamentação' em troca de 'lactação'.

\subsection{Imperativo}

O principal objetivo de um texto com função informativo-instrutiva é dar instruções ao leitor a respeito de como proceder em determinada situação. No caso das bulas de medicamentos, as instruções referem-se à ingestão do fármaco (modo, precauções etc.), bem como ao seu armazenamento e conservação. Sabe-se que, de modo geral, o que caracteriza uma instrução é o imperativo e, por isso, o emprego dessa estrutura também foi verificado contrastivamente no texto de bulas alemãs e brasileiras.

No primeiro caso, as instruções são expressas com o uso do que é o imperativo em sua forma mais comum, tratando sempre o leitor por Sie. Sendo assim, tem-se, por exemplo, Legen Sie die Tablette mit der Bruchkerbe nach oben auf eine harte, flache Unterlage (z. B. einen Teller). Uma pequena variação nessa construção pode ocorrer com a inserção da palavra bitte junto ao imperativo, como em Bitte sprechen Sie mit Ihrem Arzt oder Apotheker, wenn Sie den Eindruck haben, dass die Wirkung von Paracetamol-CT 500 mg zu stark oder zu schwach ist. Analisando alguns desses exemplos, nota-se que o imperativo com bitte aparece frequentemente no texto e, em todas as ocasiões, está especificamente 


\section{Cintra, A. D - Bulas de medicamentos}

ligado a uma instrução que estabelece algum tipo de relação entre o paciente/leitor e seu médico ou farmacêutico, ou seja, quando é necessário que o leitor pergunte ao médico ou se informe/fale com um profissional de saúde.

Uma hipótese para tal peculiaridade é que, como a informação ou instrução desejada pelo leitor não está ou (não pode estar) no texto da bula para o paciente, a ordem é que ele se dirija a um profissional da área a fim de obtê-las; nesses casos, o paciente deverá se deslocar até outro agente e, em certa medida, a bula deixa de cumprir seu papel. HERGET; ALEGRE (2010: s.1.) também atentam para o fato de que esse gênero não permite esclarecimentos individuais devido ao grande e heterogêneo público ao qual se destina e, portanto, quaisquer dúvidas específicas devem ser obtidas de maneira indireta, por meio de um profissional da saúde. Dessa forma, conclui-se que a instrução é colocada de maneira mais sutil e o imperativo é amenizado com o emprego de bitte.

Equivalente ao alemão, observa-se, nas bulas brasileiras, na maior parte das vezes, o uso do imperativo comum destinado à pessoa você, que é o pronome de tratamento mais usado na maioria das bulas consultadas, como em "Não exceda 5 comprimidos, em doses fracionadas, em um período de 24h". Entretanto, chamam a atenção muitas construções do imperativo com o infinitivo, por exemplo, "Proteger da luz e umidade". A ocorrência dessas últimas em uma mesma bula é simultânea ao primeiro uso, de modo que não é possível delimitar situações específicas nas quais cada um é empregado. Contudo, o que fica evidente é a pessoalidade de um e a impessoalidade de outro, sendo que o primeiro indica uma tentativa de aproximação do texto ao leitor a fim de ganhar sua adesão às instruções e o segundo, a manutenção de uma generalização nesse texto devido àquela característica do gênero em não tratar de informações específicas, mas sim gerais, que interessem a todos os grupos que compõem o público. 


\section{Cintra, A. D - Bulas de medicamentos}

\subsection{Verbos modais}

Durante a análise linguística das 10 bulas brasileiras e 10 bulas alemãs do corpus deste trabalho, chamou a atenção o fato de que, além das construções com o imperativo outra forma de transmitir tais informações se dá por meio do emprego de verbos modais. Sendo assim, optou-se por verificar quais desses verbos são mais frequentemente utilizados nos textos das bulas em português e em alemão e quais efeitos suas respectivas escolhas trazem para o significado da afirmação.

Nas bulas alemãs, foram encontrados quatro verbos modais diferentes (sollen/ sollten, müssen, dürfen, können), além do mögen/ möchten, que em todas elas apareceu somente na oração Heben Sie die Packungsbeilage auf. Vielleicht möchten Sie diese später nochmals lesen e, por isso, não será incluído na análise subsequente. Nas bulas brasileiras, entretanto, foram identificados apenas dois verbos modais, poder e dever.

Os verbos auxiliares são classificados entre modais centrais e semi-modais (ou modais periféricos) e tem a finalidade de determinar "com maior rigor o modo como uma ação é realizada" (AMORIM; ROCHA, 2011: 718). Segundo VIANA (2008: 68), os verbos auxiliares semi-modais são, na verdade, “expressões idiomáticas fixas que podem também ter comportamento similar ao dos verbos auxiliares modais centrais", tanto sintaticamente quanto semanticamente.

Modais e semi-modais podem, por exemplo, exprimir ideias como permissão/ possibilidade/ habilidade, obrigação/ necessidade e volição/ predição; na língua alemã, os verbos modais mais frequentes são können, wollen, sollen, dürfen, müssen e mögen, além dos semi-modais, como brauchen, já no português, tem-se 'poder' e 'dever' na função de

modais, ao lado de 'ter que/de', 'precisar de', 'permitir' (é permitido que), 'necessitar' (é necessário que) na função de semi-modais. Devido a uma característica das próprias línguas, é possível observar que, no alemão, há um maior número de verbos modais centrais para expressar obrigação/ necessidade (sollen, dürfen, müssen), ao passo que, no português, apenas um modal central detém esse traço semântico (dever). Esse fato reflete-se, 


\section{Cintra, A. D - Bulas de medicamentos}

consequentemente, no uso cotidiano de tais verbos, pois enquanto na língua alemã há, pelo menos, três verbos para expressar diferentes nuances do conceito necessidade/ obrigação, na língua portuguesa apenas um verbo precisa suprir essa condição. Dessa forma, temos as seguintes correspondências nos textos das bulas de medicamentos:

\begin{tabular}{|c|c|c|c|}
\hline Usos (alemão) & Modais (alemão) & Modais (português) & Usos (português) \\
\hline $\begin{array}{l}\text { alertas e conselhos/ } \\
\text { recomendações }\end{array}$ & sollen & \multirow{3}{*}{ dever } & \multirow{3}{*}{$\begin{array}{l}\text { alertas, recomendações } \\
\text { instruções, advertências, } \\
\text { precauções }\end{array}$} \\
\hline $\begin{array}{l}\text { instruções } \\
\text { advertências }\end{array}$ & müssen & & \\
\hline $\begin{array}{l}\text { instruções } \\
\text { precauções }\end{array}$ & dürfen & & \\
\hline efeitos colaterais & können & poder & efeitos colaterais \\
\hline
\end{tabular}

Dado que sollen, müssen e dürfen abrangem o significado geral de obrigação ou necessidade, cada um deles expressa diferentes matizes desse conceito, por exemplo, em orações que compõem o gênero das bulas de medicamentos. O verbo sollen indica que tal afirmação trata-se, mais especificamente, de um alerta (Bis dahin soll die erneute Anwendung von Schmerzmitteln unterbleiben und danach nicht ohne ärztlichen Rat erfolgen); repare que, nos textos analisados, foram encontradas muitas ocorrências desse verbo no conjuntivo (sollten), o que dá um caráter de recomendação ou conselho ao alerta (Bei Beschwerden, die länger als 3 Tage anhalten, sollte ein Arzt aufgesucht werden). Já o verbo müssen é o que traz um tom mais incisivo dos três, fazendo com que o leitor entenda que a instrução é muito importante e, por isso, deve necessariamente ser seguida (Bei Beschwerden Niereninsuffizienz, (Kreatinin-Clearance $<10 \mathrm{ml} / \mathrm{min}$ ) muss ein Dosisinterval von mindestens 8 Stunden eingehalten werden). Finalmente, o verbo dürfen transmite a ideia de precaução na sentença (Das Arzneimittel darf nicht im Abwasser oder Haushaltsabfall entsorgt werden). Dessa forma, pode-se inferir que, entre eles, há uma gradação da obrigatoriedade/ necessidade, passando de uma recomendação (sollten), à qual o paciente 


\section{Cintra, A. D - Bulas de medicamentos}

pode decidir se irá aderir ou não, para um alerta (sollen), cuja adesão é aconselhável, porém ainda não obrigatório, e de uma precaução (dürfen) altamente aconselhável para uma instrução (müssen) que deve, necessariamente, ser cumprida. Na língua alemã, existe, então, o seguinte esquema: sollen/ sollten < dürfen < müssen.

No português, entretanto, o verbo dever engloba esses matizes, fazendo com que, em comparação à língua alemã, haja a proporção 3:1. Na situação dos textos das bulas, por exemplo, recomendações, instruções, advertências e precauções são veiculadas por meio deste único verbo e percebidas com o auxílio do contexto: Você não deve tomar

se tiver hipersensibilidade ao paracetamol ou aos outros componentes da fórmula (recomendação); Você deve consultar seu médico se a dor ou febre continuarem ou piorarem... (alerta); ___ deve ser guardado em sua embalagem original (precaução); Você deve tomar os comprimidos com líquido (instrução). É importante ressaltar que, embora, na língua portuguesa, muitos verbos auxiliares semi-modais possam cumprir a função de expressar as nuances citadas, percebe-se que a preferência, nas bulas, ainda é pelos modais centrais; VIANA (2008: 67-68) esclarece que, por serem invariáveis e não terem uma forma específica para expressar tempo verbal, os modais são considerados mais atemporais do que os semi-modais e, portanto, talvez essa seja a explicação para o fato de não serem empregados semi-modais como 'ter que/de', 'precisar de', 'permitir' (é permitido que), 'necessitar' (é necessário que) para as diferentes noções de 'dever'.

A principal implicação disso é que, enquanto nas bulas alemãs as várias noções de obrigatoriedade/ necessidade são emitidas com o auxílio de verbos diferentes, nas bulas em português o contexto (como o título da seção, por exemplo) configura-se como responsável pelo sentido mais específico de um único verbo. 


\section{Cintra, A. D - Bulas de medicamentos}

\subsection{Orações subordinadas condicionais}

Nos textos das bulas de medicamentos, é muito comum que sejam encontradas orações subordinadas do tipo condicionais, sobretudo nos itens que se referem às precauções, advertências, indicações e contraindicações.

Normalmente, essas construções podem expressar uma relação de causa e consequência, uma condição necessária para a realização de outra ação, uma restrição ou uma ressalva. Segundo KOBASHI (2006: 454), existe uma associação direta "entre a ordem das sentenças no período subordinado condicional e os valores semânticos e pragmáticos" nele veiculado. São três as possíveis disposições dos elementos do período, sendo que quando a oração subordinada condicional é colocada a frente da oração principal/ núcleo do período (ou seja, quando CONDICIONAL + NÚCLEO), ela tende a expressar a noção de alguma causa ou condição que desencadeará uma consequência ou efeito; quando o arranjo do período se inverte (ou seja, quando NÚCLEO + CONDICIONAL), a ideia transmitida passa a ser de ressalva e a função da oração subordinada agora é servir como atenuante para a afirmação da principal; quando a oração subordinada do período surge intercalada à oração principal, ou seja, essa última é dividida em duas parte e a subordinada fica disposta entre as mesmas, então a oração condicional restringe o elemento topicalizado da principal, funcionando como uma observação ou um comentário em relação a ele. Dada tal situação, foi investigado se há uma posição preferencial para as orações subordinadas condicionais nos períodos dos textos das bulas estudadas e, em caso afirmativo, quais os aspectos que influenciaram tal escolha, além da motivação semântico-pragmática.

No corpus de língua alemã, verificou-se a presença de, ao todo, 27 períodos condicionais, sendo que 17 apresentaram orações subordinadas condicionais antepostas ao núcleo (ex. Wenn sich Ihr Krankheitsbild verschlimmert oder nach 3 Tagen keine Besserung eintritt, müssen Sie auf jeden Fall einen Arzt aufsuchen) e 10, a composição inversa, com as condicionais pospostas ao núcleo (ex. Fragen Sie Ihren Apotheker, wenn Sie weitere Informationen oder einen Rat benötigen). Já no corpus em língua portuguesa, foram identificados 32 períodos condicionais, dos quais 17 trazem a oração condicional anteposta 


\section{Cintra, A. D - Bulas de medicamentos}

ao núcleo (ex. Caso ocorra alguma reação de sensibilidade o medicamento deve ser descontinuado) e 15, posposta (ex. A absorção deste medicamento é mais rápida se você estiver em jejum). É importante comentar que em nenhum dos textos analisados foram encontradas orações subordinadas intercaladas. De acordo com KOBASHI (2006: 456), a predominância das condicionais antepostas deve-se, sobretudo, ao caráter prototípico dessa ordenação no período condicional, ou seja, trata-se do uso canônico da construção e isso ajuda a explicar a sua maior frequência nos textos.

Entretanto, deve-se atentar também para a nuance semântica geralmente ligada a essa disposição, que é a implicativa. Nesse caso, se estabelece uma relação causal, na qual "um estado de coisas capacita, e, assim, motiva a realização de outro” (KOBASHI 2006: 456), ou seja, há uma determinada condição para que algo ocorra. Tendo em vista o contexto ilocucional das bulas de medicamentos, principalmente dos itens que detêm um número maior de períodos condicionais (precauções, advertências, indicações e contraindicações), a relação implicativa pode ser confirmada, pois, para que um procedimento seja adotado, é necessário que, primeiramente, alguma situação o motive e leve a tal decisão.

Ainda sobre a anteposição da oração subordinada condicional ao núcleo do período, NeVES (apud FERREIRA ET AL. 2005: s.1.) afirma que, em certos gêneros textuais, como anúncios, editoriais, manuais de instrução e bulas de medicamentos, a organização da informação textual é também uma forma de estratégia para atingir o leitor e, no caso das orações condicionais antepostas, informações tidas como conhecidas por ele são normalmente colocadas a frente, a fim de ganhar a sua adesão para, depois, dados novos serem introduzidos. A autora ressalta que essa característica evidencia o 'princípio de iconicidade', pelo qual se organiza a sequência linguística fazendo com que primeiro seja enunciado o fato, já conhecido pelo informante, para, só depois, ser apontada a sua causa. (FERREIRA ET AL., 2005: s.1.). Dessa maneira, os gêneros textuais citados, por exemplo, usam também desse artifício para persuadir o leitor. Com relação às bulas, especificamente, tratase de persuadi-lo a seguir as instruções dadas.

A partir dos dados obtidos com a análise do corpus e das justificativas para a predominância das condicionais antepostas, chega-se à conclusão de que não há uma ou 


\section{Cintra, A. D - Bulas de medicamentos}

outra característica intrínseca às línguas analisadas que leva a essa disposição mais frequente do período condicional, já que tanto o corpus em alemão quanto o corpus em português apresentaram praticamente o mesmo número de ocorrências, mas sim, a função do gênero em questão.

\section{Considerações finais}

Ao adotar o par linguístico alemão-português para estudar contrastivamente o gênero bula de medicamento, foi questionado se haveria, de fato, diferenças significativas nesses dois contextos, ainda que se trate do mesmo gênero textual. A partir das análises macro e microestruturais, foi possível constatar que essas diferenças existem e configuram-se de dois modos: as divergências relacionadas à escolha das informações e seu modo de organização no texto (macroestrutura) são diretamente influenciadas pela legislação de cada país e as divergências microestruturais podem estar diretamente relacionadas à variante língua.

Conforme foi visto no estudo do gênero, uma das características atualmente intrínseca às bulas de medicamento são as prescrições jurídicas como marca cultural desse gênero textual. Tanto na Alemanha quanto no Brasil, as bulas são fortemente influenciadas por regulamentações que determinam, por exemplo, quais os componentes obrigatórios desse tipo de texto, como as informações serão organizadas e como serão transmitidas ao usuário do medicamento. Dado que essas prescrições jurídicas estão de acordo com as leis do país, é evidente que as bulas brasileiras e alemãs apresentem diferenças com relação a isso, ou seja, cada uma terá sua composição e escrita diretamente influenciadas por regulamentações dos órgãos responsáveis da Alemanha e do Brasil, respectivamente. Já as diferenças microestruturais são motivadas, sobretudo, pela variante língua, ou seja, fenômenos ocorridos no sistema de cada uma das línguas em análise provocam, nos textos, diferenças com relação a outro sistema linguístico, como por exemplo, os diferentes usos dos verbos modais e a maior ou menos necessidade de combinar termos técnicos aos seus 


\section{Cintra, A. D - Bulas de medicamentos}

respectivos termos cotidianos, tendo em vista o par linguístico português-alemão em bulas de medicamentos.

Ainda de acordo com os resultados das análises, as semelhanças, tanto macro quanto microestruturais, justificam-se normalmente por um aspecto característico do próprio gênero textual. Dessa maneira, ao final da pesquisa, também ficou evidente a importância do estudo do gênero antes de iniciar as análises contrastivas e, nesse sentido, a metodologia para trabalhos em textologia constrastiva é válida também por incorporar essa etapa logo entre os primeiros procedimentos. O fato é que muitas informações obtidas a partir do estudo detalhado do gênero (função, situação comunicativa, interlocutores etc.) auxiliam na explicação de algumas escolhas linguísticas dos textos, principalmente naquelas que se mostram semelhantes no par linguístico adotado. Além disso, percebe-se que uma análise contrastiva que leve em consideração apenas aspectos linguístico-textuais não é suficiente, pois há uma dimensão intercultural - como a influência das prescrições jurídicas nas bulas que deve ser contemplada para que haja um estudo mais verossímil do texto.

A ideia de adotar a bula de medicamento como tipo textual a ser analisado desenvolveu-se a partir do fato de que esta se constitui como um gênero de uso diário, com função informativo-instrutiva e, por isso, de alta relevância para a sociedade, entretanto, é vista, muitas vezes, como um texto problemático devido, sobretudo, à linguagem técnica e, consequentemente, à dificuldade de compreensão do texto por parte do cidadão comum, um paradoxo que motivou substancialmente este projeto. Tendo em vista os resultados da análise linguística contrastiva entre a bula alemã e a bula brasileira, será possível, por exemplo, identificar quais estratégias de redação tornam a comunicação realmente eficiente e dar início, dessa forma, a estudos que podem amenizar o problema acima exposto. Consequentemente, pesquisas como esta reforçariam a importância da análise linguística na elaboração das bulas, contribuindo assim para uma interdisciplinaridade ainda pouco praticada nessa área. Além disso, pesquisas no âmbito da textologia contrastiva, que optam por analisar contrastivamente textos provenientes de diversas culturas são bastante produtivas para os estudos e a prática da tradução. Segundo REICHMANN (2009: 117), a textologia contrastiva e a tradutologia mantêm uma relação mútua de complementaridade, 


\section{Cintra, A. D - Bulas de medicamentos}

uma vez que os resultados advindos dos estudos da primeira contribuem significativamente para a teoria e prática adequada da segunda, enquanto essa forneceria subsídios, materiais e ideias para a realização de pesquisas na outra área. A tradutologia tende a se beneficiar com pesquisas contrastivas em linguística textual, sobretudo devido a informações de cunho intercultural, como por exemplo, relacionadas à organização textual, convenções comunicativas e estilos próprios de determinada cultura.

Sendo assim, tendo em vista o gênero das bulas, colocam-se como possibilidades de pesquisas futuras, principalmente, a diversificação das microestruturas analisadas, o aprofundamento contrastivo das que já se destacam como potenciais itens de estudo e a ampliação do corpus. Em uma perspectiva mais geral, muitos autores, como ADAMZIK (2010) ECKKRAMMER (2009), BRINKER (2010) e FANDRYCH (2011) sugerem a necessidade de estender os estudos contrastivos a outros gêneros textuais, analisando suas convenções linguísticas macro e microestruturais em diferentes culturas e relacionando variados pares linguísticos.

\section{Referências bibliográficas}

ADAMZIK, K. Trad. Wieser, H. P. Questões fundamentais da Textologia contrastiva. In: Org. WIESER, H. P. \& KoCH, I. G. V. Linguística Textual: Perspectivas Alemãs. Rio de Janeiro: Nova Fronteira, 2009, p. 233-288.

AMORIM, C. M. S.; RochA, L. H. P. Auxiliaridade em Perspectivas. In: Anais do VII Congresso Internacional da Abralin. Curitiba, 2011, p. 717-727. Disponível em: <http://www.abralin.org/abralin11_cdrom/artigos/Carmelita_Amorim.PDF>. Acesso em 05 julho 2012.

ANVISA. Bulas de Medicamentos no Brasil: Resolução - RDC n 47/2009. setembro 2009. Disponível em <http://www.anvisa.gov.br/medicamentos/bulas/rdc_47.pdf>. Acesso em 29 maio 2012.

BERG-SCHMIDT, J. Erläuterung zur Textsorte ,Packungsbeilage für Fertigarzneimittel ${ }^{`}$. In: Wissenstransfer Arzeimittel. Untersuchungen zu Packungsbeilagen. Dissertation zur Erlangung der Doktorwürde. Universität Trier, 2003, p. 54-59.

BRINKER, K. Analyse von Textsorten. In: Linguistische Textanalyse. Eine Einführung in Grundbegriffe und Methoden. Berlin: Erich Schmidt Verlag, 2010, p. 120 - 136. 


\section{Cintra, A. D - Bulas de medicamentos}

CAldeira, T. R., Neves, E. R. Z., Perrini, E. Evolução histórica das bulas de medicamentos no Brasil. In: Caderno de Saúde Pública. Rio de Janeiro, v. 24, n. 4, 2008, p. 737-743. Disponível em <http://www.scielo.org/pdf/csp/v24n4/03.pdf>. Acesso em 22 maio 2011.

DEUTSCHLAND. Gesetz über den Verkehr mit Arzneimitteln (Arzneimittelgesetz - AMG), 12. 12. 2005. Disponível em <http://www.gesetze-iminternet.de/bundesrecht/amg_1976/gesamt.pdf>. Acesso em 15 maio 2012.

ECKKRAMMER, E. M.; Trad. Wieser, H. P. Aspectos e perspectivas da comparação interlingual e intermidiática de gêneros textuais. In: Org. WIESER, H. P.; KOCH, I. G. V. Linguística Textual: Perspectivas Alemãs. Rio de Janeiro: Nova Fronteira, 2009, p. 289-315.

EUROPEAN COMISSION. Guideline on the readability of the label and package leaflet of medicinal products for human use. Revision 1. Pharmaceutical Committee: Brussels, 01.12.2009. Disponível em <http://ec.europa.eu/health/files/eudralex/vol2/c/2009_01_12_readability_guideline_final_en.pdf >. Acesso em 15 maio 2012.

EUROPÄISCHE UNION. Richtlinie 2004/27/EG des Europäischen Parlaments und des Rates vom 31. März 2004 zur Änderung der Richtlinie 2001/83/EG zur Schaffung eines Gemeinschaftskodexes für Humanarzneimittel. Disponível em <http://ec.europa.eu/health/files/eudralex/vol-1/dir_2004_27/dir_2004_27_de.pdf >. Acesso em 31 julho 2012.

FANDRYCH, C. \& THURMAIR, M. Konzeption und Ansatz der vorliegenden Studie. In: FANDRYCH, C. ; THURMAIR, M. Textsorten im Deutschen: Linguistische Analysen aus sprachdidaktischer Sicht. Strauffenburg Verlag: Tübingen, 2011. p. 13-34.

FERreira, V. P; MotTA, D. G. N.; RodrigueS, V. V. Ordem e papel dos conectores nas condicionais. In: Cadernos do VIII Congresso Nacional de Linguística e Filologia. Vol. IX, $\mathrm{n}^{\circ} 15,2005$, p. 1-8. Disponível em: < http://www.filologia.org.br/ixcnlf/15/14.htm>. Acesso em 03 julho 2012.

FIX, U. Stand und Entwicklungstendenzen der Textlinguistik (I). In: Deutsch als Fremdsprache: Zeitschrift zur Theorie und Praxis des Deutschsunterrichts für Ausländer. Hsg. Herder Institut, interDaF e. V. am Herder Institut, Universität Leipzig. München/Berlin: Langenscheidt, 46. Jahrgang, 2009. 1. Quartal, Heft 1, p. 11-20.

Gonçalves, S. A.; Melo, G.; ToKarski, M. H. L.; Barbosa-Branco, A. Bulas de medicamentos como instrumento de informação técnico-científica. In: Revista de Saúde Pública. Edusp, v. 36, n. 2, 2002. Disponível em <http://www.scielo.br/pdf/rsp/v36n1/8113.pdf >. Acesso em 21 fevereiro 2012.

Hartmann, R. R. K. Contrastive Textology. In: Contrastive Textology: Comparative discourse analysis in applied linguistics. Heidelberg: Gross, 1980, p. 31-40.

Herget, K; Alegre, T. Comparison of Textual Patterns in German and Portuguese Medical Texts. Translation Journal. Volume 14, $\mathrm{n}^{\circ} 4$, out 2010. Disponível em <http://www.bokorlang.com/journal/54medical.htm>. Acesso em 27 junho 2012.

KIRK, B. Chronik des Contergan-Falls: Tragödie-Katastrophe-Skandal? In: Der Conterganfall: eine unvermeidbare Arzneimittelkatastrophe? Zur Geschichte des Arzneistoffs Thalidomid. Dissertation an der Universität Greifswald, 1998. Disponível em <http://www1.wdr.de/themen/archiv/sp_contergan/contergan176.html>. Acesso em 04 março 2012. 


\section{Cintra, A. D - Bulas de medicamentos}

KoBASHI, C. M. As orações condicionais no português popular: ordenação e significado. In: Estudo Linguísticos $X X X V$. Organizado pelo Grupo de Estudos Linguísticos do Estado de São Paulo, 2006, p. 454- 463. Disponível em:

<http://www.gel.org.br/estudoslinguisticos/edicoesanteriores/4publica-estudos2006/sistema06/1106.pdf>. Acesso em 23 maio 2012.

Melo, S. D.; MonTEIRo, M. J. P. O discurso acadêmico da Arqueologia em alemão e português: uma busca de acesso entre culturas? In: BATTAgLiA, M. H. V.; NomURA, M. (Org.) Estudos linguísticos contrastivos em alemão e português. São Paulo: Annablume, 2008. $1^{\mathrm{a}}$ edição.

Neubach, C. Die juristischen Rahmenkriterien. In: Deutsche und französische Packungsbeilagen: Vergleichende Fachtextanalyse von Packungsbeilagen der deutschen und französischen Sprache zwischen 1991-2007. Hamburg: Verlag Dr. Kovac, 2009, p. 37-50.

REICHMANN, T. “Marcas culturais na linguagem de especialidade”. In: Lusorama, V. 77- 78, 2009, P. $103-122$.

SCHWEIGER, K. S. Metodologia. In: Estratégias retóricas de distribuição de informação e a sinalização léxico-gramatical em introduções de dissertações de mestrado na área de alemão da USP/São Paulo e da LMU/Munique. São Paulo, 2011. 257 f. Tese de doutorado (Língua e Literatura Alemã). Faculdade de Filosofia, Letras e Ciências Humanas, Universidade de São Paulo, p. 76-96.

Silva, T., Dal-Pizzol, F., Bello, C. M., Mengue, S. S., Schenkel, E. P. Bulas de medicamentos e a informação adequada ao paciente. In: Revista de Saúde Pública. Edusp, v. 34, n. 2, 2000, p. 184-189. Disponível em <http://www.scielosp.org/pdf/rsp/v34n2/1955.pdf>. Acesso em 18 fevereiro 2012.

VIANA, V. P. Verbos modais. In: Verbos modais em contraste: Análise de corpus da escrita de universitários em inglês. Dissertação (Mestrado em Letras). Pontifícia Universidade Católica do Rio de Janeiro, Rio de Janeiro, 2008, p. 60-93. Disponível em <http://www2.dbd.pucrio.br/pergamum/tesesabertas/0610483_08_cap_04.pdf>. Acesso em 05 julho 2012.

Volpato, L., MARtins, L., Mialhe, F. Bulas de medicamentos e profissionais de saúde: ajudam ou complicam a compreensão dos usuários? In: Revista de Ciências Farmacêuticas Básica e Aplicada. Editora UNESP, v. 30, n. 3, 2009. Disponível em <http://servbib.fcfar.unesp.br/seer/index.php/Cien_Farm/article/viewFile/623/887>. Acesso em 18 fevereiro.

Corpus em português:

DÔRICO: Paracetamol. Responsável técnico: Antonia A. Oliveira. Suzano: Sanofi Aventis Farmacêutica Ltda. Bula de medicamento.

PARACETAMOL. Responsável técnico: Dra. Erika Santos Martins. São Bernardo do Campo: Ems S/A., 2011. Bula de medicamento.

PARACETAMOL. Responsável técnico: Dra. Miriam Onoda Fujisawa. Campinas: Medley Indústria Farmacêutica Ltda. Bula de medicamento.

PARACETAMOL. Responsável técnico: Alberto Jorge Garcia Guimarães. São Paulo: Biosintética Farmacêutica Ltda., 2011. Bula de medicamento. 


$$
\text { Cintra, A. D - Bulas de medicamentos }
$$

PARACETAMOL. Responsável técnico: Charles Ricardo Mafra. Pouso Alegre: Cimed Indústria de Medicamentos Ltda. Bula de medicamento.

PARACETAMOL. Responsável técnico: Marcos Leite de Sousa Filho. São Paulo: Zydus Healthcare Brasil Ltda. Bula de medicamento.

SONRIDOR: Paracetamol. Responsável técnico: Mariluce L. Ricardo. Rio de Janeiro: GlaxoSmithKline Brasil Ltda. Bula de medicamento.

TYLAFLEX: Paracetamol. Responsável técnico: Dr. Jadir Vieira Junior. Juiz de Fora: Medquímica Indústria Farmacêutica Ltda. Bula de medicamento

TYLENOL: Paracetamol. Responsável técnico: Marcos R. Pereira. São José dos Campos: JanssenCilag Farmacêutica. Bula de medicamento.

VICK PYRENA: Paracetamol. Responsável técnico: Silvia C. M. de Freitas. Louveira: Procter \& Gamble do Brasil S. A. Bula de medicamento.

Corpus em alemão:

PARACETAMOL 500 - 1A Pharma. Oberhaching: 1A Pharma GmbH, 2008. Bula de medicamento.

PARACETAMOL ABZ. Blauberen: AbZ- Pharma GmbH, 2008. Bula de medicamento.

PARACETAMOL BETA 500. Augsburg: betapharm Arzneimittel GmbH, 2009. Bula de medicamento.

PARACETAMOL BC. Berlin: Berlin-Chemie AG, 2008. Bula de medicamento.

PARACETAMOL CT. Berlin: CT Arzneimittel GmbH, 2008. Bula de medicamento.

PARACETAMOL DURA 500 mg. Darmstadt: Mylan dura GmbH, 2008. Bula de medicamento.

PARACETAMOL 500 mg HEUMANN TABLETTEN. Nürnberg: Heumann Pharma, 2009. Bula de medicamento.

PARACETAMOL SAFT 4\% LICHTENSTEIN. Berlin: Winthrop Arzneimittel, 2005. Bula de medicamento.

PARACETAMOL-RATIOPHARM 500 mg TABLETTEN. Blaubeuren: ratiopharm GmbH, 2008. Bula de medicamento.

PARACETAMOL STADA 500 mg TABLETTEN. Bad Vilbel: STADApharm GmbH, 2009. Bula de medicamento.

Recebido em 01/08/2012

Aprovado em 04/09/2012

Pandaemonium, São Paulo, v. 15, n. 20, Dez. /2012, p. 224-261 - www.fflch.usp.br/dlm/alemao/pandaemoniumgermanicum 